\title{
Ketamine abuse potential and use disorder
}

\author{
Yu Liu, Deyong Lin', Boliang Wu ${ }^{1}$, Wenhua Zhou ${ }^{1,2 \star}$
}

1.Laboratory of Behavioral Neuroscience, School of Medicine, Ningbo University, Ningbo 315211, P.R. China

2.Ningbo Addiction Research and Treatment Center,Ningbo 315010, P.R. China

${ }^{*}$ Communicating authors:

Wenghua Zhou

Email:whzhou@vip.163.com

Tel: 86-574-87609588

Fax: 86-574-87345902

\section{Acknowledgments}

This work was supported in part by the National Natural Science Foundation of China (U1132602), the Program for Innovative Research Team in Ningbo City (2015C110026), Zhejiang Provincial Key Laboratory of Pathophysiology (Ningbo University School of Medicine) and K.C.Wong Magna Fund in Ningbo University.

Conflicts of interest: None 


\begin{abstract}
Ketamine is a noncompetitive antagonist of $\mathrm{N}$-methyl-D-asparate (NMDA) receptor and has been long used as an anesthetic agent in humans and veterinary medicine. The present article reviews the epidemiology, pharmacology, neurochemistry, and treatment of ketamine abuse. Ketamine has a unique mood controlling property and a number of studies have demonstrated a significant and rapid antidepressant effect of ketamine. However, the therapeutic value of ketamine to treat psychiatric disorders faces a major challenge that ketamine also owns significant reinforcing and toxic effects. Its abuse has posted severe harms on individuals and society. Disrupted learning and memory processing has long been related with ketamine use. It is hypothesized that ketamine blocks NMDA receptors on gamma-aminobutyric acid (GABA) neurons inside the thalamic reticular nucleus, which leads to disinhibition of dopaminergic neurons and increased release of dopamine. Currently, there is no specific treatment for treating every ketamine patient presenting peripheral toxicity. Interestingly, ketamine psychotherapy has been suggested to be a promising approach to treat addiction of other drugs. Future research can continue to develop creative ways to investigate potential mechanism and treatments related to ketamine abuse that have posted severe individual and social harms.
\end{abstract}


Ketamine was firstly synthesized by Calvin Stevens of the Parke-Davis Pharmaceutical Company in 1962(Copeland and Dillon, 2005). In chemical structure, Ketamine (2-chlorphenyl-2-methylamino-cyclohexanone) is a phencyclidine (PCP) derivative(Rowland, 2005). Ketamine is a noncompetitive antagonist of $\mathrm{N}$-methyl-D-asparate (NMDA) receptor and has been long used as an anesthetic agent in humans and veterinary medicine (Kurdi et al., 2014). In addition, ketamine, as a dissociative anesthetic, has a unique psychological effect which displays both mood controlling and reinforcing properties (Coyle and Laws, 2015; Jansen and Darracot-Cankovic, 2001).Since the first placebo-controlled trial investigating the antidepressant effect of ketamine in 2000 , a number of studies have demonstrated a significant and rapid antidepressant effect of ketamine(Berman et al., 2000; Costi et al., 2015).In line with the anti-depressant effect of ketamine, the use of subanethetic ketamine infusions has also been extended from treatment-resistant depression to bipolar disorder, anxiety and chronic pain (Romeo et al., 2015; Sheehy et al., 2015; Zgaia et al., 2015). However, ketamine and its derivative, methoxetamine, has also been shown to serve as a reinforcing stimulus to induce self-administration and conditioned place preference in rats, suggesting its high potential of drug abuse (Botanas et al., 2015; De Luca and Badiani, 2011; Venniro et al., 2015; Winger et al., 2002; Young and Woods, 1981). Due to its reinforcing and rewarding properties, ketamine has become a recreational drug in the context of "raves" and the non-medical use of ketamine has grown steadily worldwide in the past a few decades (Bokor and Anderson, 2014; Chakraborty et al., 2011; Liu et al., 2006; Pavarin, 2006; Rome, 2001).In addition to its abuse potential, ketamine was proved to produce neurological and peripheral toxicity (Gable, 2004; Morgan et al., 2010). The present review focuses on the brain neurocircuitry that is engaged at the reinforcing effect of ketamine associated with its abuse.

\section{Social harms of ketamine abuse}

The recreational dose of ketamine is approximately $15 \%$ to $20 \%$ lower than its anesthetic dose. Due to its anesthetic and reinforcing properties, ketamine has become a commonly abused drugs in many parts of the world. The US survey in 
2006estimated that approximately 2.3 million teens and adults used ketamine in their lifetime (Administration, 2008). The number of ketamine-related death has increased 10 foldsin UK from 1999 to 2008 (Morgan et al., 2012). According to an Australian survey, $40 \%$ of party drug users reported the use of ketamine (Breen et al., 2008). In the past decade, ketamine abuse has also been spread over the countries and regions in Asia. There was almost four-fold increase in ketamine users in Malaysia from 2006 to 2012 (Singh et al., 2013). Ketamine abuse started to emerge in China in 90s and Hong Kong has been one of the hardest hit regions in the country (Tang et al., 2015; Tang et al., 2015). In Hong Kong along, over 2000 cases were reported for ketamine abuse in 2013 and 2014 (Tang et al., 2015). The percentage of ketamine users among all registered drug users have also increased from $21.5 \%$ in 2001 to $40 \%$ in 2009 in mainland China (Jia et al., 2015). The rapidly deteriorating condition of ketamine abuse has resulted in the change of ketamine status from a class II to class I psychotropic drug in China.

Although ketamine is a relatively safe substance in medical settings, its abuse has posted severe harms on individuals and society (Morgan et al., 2012). One of the major concerns is driving under the influence of ketamine. The popularity of ketamine as a club drug has also led to an increased reports of driving under the influence of ketamine. For example, ketamine was the third most used illicit drugs among drivers tested positive for psychoactive drugs in Shanghai, China (Zhuo et al., 2010). In a survey conducted in Scotland, 36\% of 122 partygoers confirmed driving after using ketamine. In Hong Kong, 9\% of drivers involving fatal car crash were tested positive for ketamine (Cheng et al., 2005). The risks of ketamine associated traffic accident could be related to its impairing effect on executive cognitive functions, decreased attention, and impaired memory functioning (Giorgetti et al., 2015; Penning et al., 2010). In addition, ketamine has also been suggested to produce enhanced sex experience which could lead to drug-facilitated sexual assault (Bokor and Anderson, 2014). An increased incidence of unproductive sex among gay men with ketamine use has also caused concerns in many countries (Daskalopoulou et al., 2014; Lea et al., 2013; Pappas and Halkitis, 2011; Xu et al., 2014). 


\section{Psychological and physiological effects of ketamine}

Ketamine has a plasma half-life of 2-4 hours and a distribution half life of 7-11 minutes (Copeland and Dillon, 2005). Administration routes of ketamine commonly include intravenous, intramuscular, snorting, and smoking (Bokor and Anderson, 2014). The predominant route of ketamine administration for recreational use is intranasal and intravenous injection is rather rare (Reynaud-Maurupt et al., 2007). The primary psychological effect of ketamine is anesthesia and sedation. It should be noted that the use of ketamine for human anesthesia is often associated with hallucinations after waking up (Powers lii et al., 2015). Reports of "out-of-body" experiences have been consistently associated with recreational use and abuse of ketamine (Muetzelfeldt et al., 2008; Wilkins et al., 2012). For unauthorized use of ketamine, low dose is associated with a feeling of relaxation, which is so called "K-land"; whereas high dose produces a dreamlike state called a "K-hole" (Britt and McCance-Katz, 2005). The dissociative anesthetic characteristics of ketamine greatly contribute to ketamine abuse. In addition to the psychoactive effects of ketamine, disrupted learning and memory processing has long been related with ketamine use (Morgan and Curran, 2006). An acute dose of ketamine has been demonstrated to induce cognitive impairments in healthy volunteers and cognitive deficits are also observed in frequent ketamine users (Curran and Morgan, 2000; Liang et al., 2013; Morgan et al., 2010). Particularly, verbal learning impairment and decreased performance on spatial memory was strongly correlated with estimated lifetime ketamine use (Chan et al., 2013; Morgan et al., 2010). Interestingly, ketamine-induced cognitive impairment has been suggested to have therapeutic value. Intravenous ketamine has rapid effects on explicit and inexplicit suicidal cognition, which makes it an attractive candidate for depressed patients at imminent risk of suicide (Price et al., 2014; Solé et al., 2015). Furthermore, chronic use of ketamine has been suggested to produce schizophrenia-like positive and negative symptoms, including hallucinations, detachment, delusions, amotivations et al. Auditory verbal hallucinations, a hallmark symptom of schizophrenia, have also been reported in healthy volunteers with high doses of ketamine (Powers lii et al., 2015). 
Ketamine also has systemic effects on a number of organs. Ketamine stimulates the cardiovascular system, due to decreased catecholamine reuptake. These changes lead to increased heart rate and blood pressure (Mayberg et al., 1995). As a matter of fact, the most complaints among ketamine abusers presenting at the Emergency Department were chest pains, palpitations, and tachycardia (Weiner et al., 2000). The symptoms were often transient and patients were often discharged within hours (Gable, 2004). Unlike first-time users of ketamine, patients with a history of chronic ketamine use commonly reported abdominal pain and urinary tract symptoms (Skeldon and Goldenberg, 2014). A number of cases reports suggest that ketamine abuse can cause suprapubic pain, dysurria and hematuria (Mason et al., 2010; Peng et al., 2014; Yek et al., 2015). Radiology results revealed decreased bladder volume, bladder wall thickening, musosal enhancement, dilation of ureter, and perivesical inflammation in ketamine abusers (Huang et al., 2014; Wu et al., 2012). Based on cytoscopy findings, erythema, edema, and epithelial inflammation are commonly associated with chronic ketamine use (Chu et al., 2008; Shahani et al., 2007). One possible mechanism underlying renal toxicity of ketamine is due to the direct toxic effects of ketamine and its metabolites (Bokor and Anderson, 2014; Gable, 2004). Marked alterations in epithelial cell-to-cell adhesion and cell coupling in the proximal kidney are also thought to be associated with renal toxicity of ketamine (Hills et al., 2013).Both clinical and animals studies confirm liver damage caused by chronic use of ketamine. For example bile duct dilatation, microscopic bile duct injury, and even significant liver fibrosis have been found among ketamine abusers (Wong et al., 2015).Fatty degeneration of liver cells, fibrosis and increase in liver glutamicoxaloacetic transaminase, proliferative cell nuclear antigen and lactate dehydrogenase were reported in rats with 16-weektreatment with ketamine and alcohol (Wai et al., 2012).Mitochondrial dysfunction has been suggested to result in the underlying hepatotoxcity of ketamine (Chang et al., 2009; Kalkan et al., 2013; Lee et al., 2009; Venâncio et al., 2013).

\section{Reinforcing effects of ketamine}

Although the pharmacological and psychological profile of ketamine is rather 
different from that of psychostimulants and opioid drugs, some of its actions are more or less similar to these drugs. Ketamine, for example, has been reported to increase dopamine efflux and inhibit dopamine uptake in the nucleus accumbens (Hancock and Stamford, 1999). The drug self-administration (SA) model mimics voluntary drug-taking behavior in animals and has been used widely to assess the reinforcing and motivational aspects of drugs (Bossert et al., 2013; Dreizin, 1978). The activation of central dopaminergic system and rising popularity of ketamine use also lead the researchers to predict that ketamine could serve as a reinforcer to initiate and maintain self-administration behavior in the animals. More half a century's research has been consistently demonstrated self-administration of ketamine in monkeys, rats, and dogs under various procedures (Broadbear et al., 2004; Huang et al., 2015; Li et al., 2015; Moreton et al., 1977; Risner, 1982; Young et al., 1981).The behavioral paradigm of conditioned place preference (CPP) is also commonly used to evaluate the motivational properties (i.e. rewarding or aversive effects) of drugs. This technique is based on the formation of an association of the rewarding effect of a drug with a specific environment which will result in a preference for this environment (Bardo and Bevins, 2000; Liu et al., 2008; Tzschentke, 2007; van der Kam et al., 2007). Like many drugs of abuse, ketamine also served as a positive reinforcing agent inducing conditioned place preference in rats (Guo et al., 2016; Suzuki et al., 1999; van der Kam et al., 2009). Interestingly, female rats showed a higher conditioned place preference score of ketamine than male rats (Guo et al., 2016)

\section{Neurochemical effects of ketamine abuse}

The reinforcing properties of drugs contribute to the behavioral mechanism underlying the addictive properties of abused drugs (Bergman and Paronis, 2006). Positive reinforcing effect of drugs is essential to initiate and maintain drug taking behaviors (Deneau et al., 1969). Negative reinforcing effect of drugs is also a key to maintain drug taking behavior and to reduce discomfort associated with drug withdrawal (Thompson and Schuster, 1964; Weeks, 1962). The positive reinforcing properties of ketamine include dissociative anesthetic and euphoria effects. The most common discomfort following ketamine abstinence was fatigue, poor appetite and 
drowsiness (Chen et al., 2014). Craving, anxiety, sleeping problems, and dysphoria were also common psychological symptoms following the cease of ketamine use (Chen et al., 2014; Tang et al., 2015). An animal study also showed that chronic ketamine administration significantly enhanced immobility during force swimming test in mice (Chatterjee et al., 2011). Indeed, the reinforcing and rewarding effects of ketamine allows the laboratory animals to exhibit behaviors of self-administration, conditioned place preference, and drug discrimination (De Luca and Badiani, 2011; van der Kam et al., 2009; Venniro et al., 2015; Yoshizawa et al., 2013).The most recognized anatomical structure for the reinforcing effects of drugs are the mesocorticolimbic dopamine systems (Cami and Farre, 2003). Ketamine, like many other psychoactive drugs, also activates the rewarding pathway in the brain (Tedesco et al., 2013). A single subanethetic dose of ketamine rapidly increased DA release in the medial prefrontal cortex of rats while repeated ketamine administration increased the basal dopamine levels (Lindefors et al., 1997; Tan et al., 2012). It is hypothesized that ketamine blocks NMDA receptors on gamma-aminobutyric acid (GABA) neurons inside the thalamic reticular nucleus, which leads to disinhibition of dopaminergic neurons and increased release of dopamine. Both dopamine D1 and D2 receptors have also been found to be increased in prefrontal cortex (PFc) and striatum respectively (Zhu et al., 2015). Dopamine D2/3 receptor availability was reported to be positively correlated with the associated psychopathological disruption evoked by subanethetic doses of ketamine in healthy young volunteers (Vernaleken et al., 2013).

A growing number of studies have revealed that GSK-3 $\beta$ may contribute to diseases that arise from dysfunctional dopamine, glutamate and serotonin transmission in the brain. GSK-3 $\beta$ has been implicated recently in the neurochemical mechanism underlying ketamine-induced neuronal toxicity and behavioral disturbance. For example, decreases in p-GSK-3 $\beta$ activity have been found in rat pups exhibiting ketamine-induced apoptosis. GSK-3 $\beta$ activation is associated with the motor, sensorimotor, and cognitive abnormalities induced by ketamine (Chan et al., 2012). In contrast, inactivation of GSK-3 $\beta$ has been shown to underlie the neuroprotective effect of erythropoietin (EPO) in ketamine-induced neurotoxicity in 
primary cortical neurons (Shang et al., 2007). Blockade of GSK-3 $\beta$ has also been shown to reduce ketamine self-administration and cue-induced reinstatement in rats (Huang et al., 2015). In a clinical setting, acute treatment with ketamine significantly increased the plasma level of $p$-GSK-3 $\beta$ in patients with major depressive disorder (Yang et al., 2013). These data support an important role for GSK-3 $\beta$ in behavioral alterations induced by ketamine.

The neuronal mechanism underlying the cognitive impairment induced by ketamine is only beginning to be understood. Neuroimaging studies revealed that acute administration of ketamine in healthy volunteers resulted in impaired verbal working and episodic memory, in conjunction with altered activities in cingulate region, striatum and frontal cortex (Honey et al., 2005; Honey et al., 2004; Northoff et al., 2005; Rowland et al., 2005). Similar to these findings in healthy volunteers, chronic ketamine users also presented disrupted frontal and medial temporal functioning, possibly specific to verbal information processing (Chan et al., 2013; Morgan et al., 2010).Pharmacological magnetic resonance imaging (PhMRI) studies have reported increases of blood-oxygen-level-dependent (BOLD) signal in frontal, hippocampal and thalamic regions following ketamine administration (Littlewood et al., 2006). In a clinical setting, decreased posterior cingulate and medial prefrontal deactivations was evident during a working memory task following ketamine administration (Anticevic et al., 1984). Perceptual distortions and delusional thoughts were correlated with increased BOLD response in the paracentral lobule (Stone et al., 2015). These studies suggest that ketamine effects on specific circuits play a major role in ketamine-induced cognitive impairment. A number of animal studies have also investigated neurochemical mechanism underlying ketamine-induced cognitive impairment. For example, interaction between nicotinic receptor (nAChR) and GABAergic system has been suggested to involve cognitive dysfunction induced by ketamine (Cloke and Winters, 2014). GABAa receptors of mPFC neurons and GABAb receptors of the CA1 neurons has also been found to involve ketamine-induced impairment of spatial and non-spatial memory (Farahmandfar et al., 2016; Khanegheini et al., 2015). Modulation of dopaminergic system is of great 
importance for cognitive functions. Ketamine-induced amnesia could be significantly decreased by both dopamine D1 and D2 receptor agonist (Farahmandfar et al., 2016; Roberts et al., 2010). Dopamine D1/D5 receptors and alpha-amino-3-hydroxy-5-methyl-4-isoxazolepropionic acid (AMPA) receptors in hippocampus are suggested to associate with spatial memory impairment induced by ketamine (Duan et al., 2013; Nakako et al., 2013).On the other hand, cognitive protective effect of ketamine on electroconvulsive shock-induced memory impairment may be associated with decreased level of neuroinflammation and soluble $A \beta$ (Zhu et al., 2015).

\section{Treatment of ketamine abuse}

Currently, there is no specific treatment for treating patients who abuse ketamine presenting peripheral toxicity. Antibiotics, non-steroidal anti-inflammatory drugs, steroids, and anticholingeric drugs have been demonstrated to be effective. In some severe and extreme cases, urinary diversion and nephroectomy may be needed. It is agreed in the literature that abstinence from ketamine abuse enables to induce a certain degree of improvement of organ damage. Interestingly, abstinence in conjunction with environmental enrichment has been shown to significantly promote recovery of cardiac and renal toxicity induced by ketamine self-administration in rats, compared with abstinence with isolation environments (Li et al., 2015). In the presence of unsuccessful attempts to control the toxicity of ketamine in practice and the need for follow-up care for life, this may reflect the greater need to include supplementary intervention into the abstinence, in order to achieve more favorable treatment outcomes. Based on the primary pharmacological action of ketamine, there are some attempts to treat ketamine addiction via the modulation of glutamatergic system. A recent study reported that a significant decrease in both the frequency and daily dosage of ketamine use in a chronic ketamine user receiving administration of lamotrigine, a glutamate release inhibitor (Huang et al., 2016). Similar to other drug use disorders, behavioral and cognitive treatments have also been the mainstream approach to manage compulsive drug-taking behaviors in patients with ketamine addiction. 
Interestingly, ketamine psychotherapy has been suggested to be a promising approach to treat addiction of other drugs. As a candidate drug for psychedelic psychotherapy, ketamine used for treating alcoholism began in the 1950s and 1960s (Krupitsky and Grinenko, 1997). A review of ten years research on ketamine psychedelic therapy (KPT) for alcoholism provided a supporting notion that KPT produced therapeutic benefits, including prolonged abstinence, favorable changes of mood and lifestyles (Krupitsky and Grinenko, 1997). In a two-year follow up study of heroin addiction, a reduced rate of relapse and marginal anti-craving effects were achieved in patients receiving a high dose of intramuscular injection of ketamine (Krupitsky et al., 2002). Furthermore, repeated KPT sessions produced more favorable outcomes among heroin addictions, compared with a single KPT session (Krupitsky et al., 2007). In a recent study, a single infusion of sub-anesthetic ketamine enabled to promote motivation to quit and reduce cue-induced craving in patients with cocaine addiction (Dakwar et al., 2014; Dakwar et al., 2014). Since there are still some conflicting results in the litterateur and the precise mechanism remains largely unknown, further studies are needed to investigate effects the potential use of ketamine in addiction of other drugs.

\section{Conclusion}

The discovery of the rapid antidepressant effect of ketamine has shed a new light onto the pathphysiology and treatment of depression. However, ketamine can be a preferred drug and lead to drug abuse. The therapeutic value of ketamine to treat psychiatric disorders faces a major challenge that ketamine also owns significant reinforcing and toxic effects. Recent mechanistic studies are beginning to investigate neurochemical mechanisms underlying ketamine abuse, including effects on NMDA receptors,GSK-3 activity, or inflammatory mediators. Future research can continue to develop creative ways to investigate potential mechanism and treatments related to ketamine abuse that have posted severe individual and social harms. The extent to which ketamine can be used as a safe antidepressant requires much greater investigation. 


\section{References}

Administration, S.A.M.H.S., (2008). The NSDUH Report Use of Specific Hallucinogens: 2006. Office of Applied Studies, Rockville, MD.

Anticevic, A., Gancsos, M., Murray, J.D., Repovs, G., Driesen, N.R., Ennis, D.J., Niciu, M.J., Morgan, P.T., Surti, T.S., Bloch, M.H., 1984. NMDA receptor function in large-scale anticorrelated neural systems with implications for cognition and schizophrenia. Mechanical Engineering Pub.

Bardo, M.T., Bevins, R.A., (2000). Conditioned place preference: what does it add to our preclinical understanding of drug reward? Psychopharmacology 153, 31-43.

Bergman, J., Paronis, C.A., (2006). Measuring the reinforcing strength of abused drugs. Mol Interv 6, 273-283.

Berman, R.M., Cappiello, A., Anand, A., Dan, A.O., Heninger, G.R., Charney, D.S., Krystal, J.H., (2000). Antidepressant effects of ketamine in depressed patients.

Biological Psychiatry 47, 351-354.

Bokor, G., Anderson, P.D., (2014). Ketamine: an update on its abuse. J Pharm Pract 27, 582-586.

Bokor, G., Anderson, P.D., (2014). Ketamine: an update on its abuse. Journal of Pharmacy Practice 27, 582-586.

Bossert, J.M., Marchant, N.J., Calu, D.J., Shaham, Y., (2013). The reinstatement model of drug relapse: recent neurobiological findings, emerging research topics, and translational research. Psychopharmacology 229, 453-476.

Botanas, C.J., Peña, J.B.D.L., Peña, I.J.D., Tampus, R., Yoon, R., Kim, H.J., Yong, S.L., Jang, C.G., Cheong, J.H., (2015). Methoxetamine, a ketamine derivative, produced conditioned place preference and was self-administered by rats: Evidence of its abuse potential. Pharmacology Biochemistry \& Behavior 133, 31-36.

Breen, C., Degenhardt, L., White, B., Bruno, R., Chanteloup, F., Fisher, J., Johnston, J., Kinner, S., Moon, C., Proufoot, P., et al., (2008). Australian party drugs trends 2003: Findings from the party drug initiative. . Sydney: National Drug and Alcohol Research Centre.

Britt, G.C., McCance-Katz, E.F., (2005). A brief overview of the clinical pharmacology of "club drugs". Subst Use Misuse 40, 1189-1201.

Broadbear, J.H., Winger, G., Woods, J.H., (2004). Self-administration of fentanyl, cocaine and ketamine: effects on the pituitary-adrenal axis in rhesus monkeys.

Psychopharmacology (Berl) 176, 398-406.

Cami, J., Farre, M., (2003). Drug addiction. N Engl J Med 349, 975-986.

Chakraborty, K., Neogi, R., Basu, D., (2011). Club drugs: review of the 'rave' with a note of concern for the Indian scenario. Indian J Med Res 133, 594-604.

Chan, K.W., Lee, T.M., Siu, A.M., Wong, D.P., Kam, C.M., Tsang, S.K., Chan, C.C., (2013). Effects of chronic ketamine use on frontal and medial temporal cognition. Addict Behav 38, 2128-2132.

Chan, K.W.S., Lee, T.M.C., Siu, A.M.H., Wong, D.P.L., Kam, C.M., Tsang, S.K.M., Chan, C.C.H., (2013). Effects of chronic ketamine use on frontal and medial temporal cognition. Addictive Behaviors 38, 2128-2132.

Chan, M.H., Chiu, P.H., Lin, C.Y., Chen, H.H., (2012). Inhibition of glycogen synthase 
kinase-3 attenuates psychotomimetic effects of ketamine. Schizophr Res 136, 96-103.

Chang, H.C., Chen, T.L., Chen, R.M., (2009). Cytoskeleton interruption in human hepatoma HepG2 cells induced by ketamine occurs possibly through suppression of calcium mobilization and mitochondrial function. Drug Metab Dispos 37, 24-31. Chatterjee, M., Ganguly, S., Srivastava, M., Palit, G., (2011). Effect of 'chronic' versus 'acute' ketamine administration and its 'withdrawal' effect on behavioural alterations in mice: implications for experimental psychosis. Behav Brain Res 216, 247-254. Chen, W.Y., Huang, M.C., Lin, S.K., (2014). Gender differences in subjective discontinuation symptoms associated with ketamine use. Subst Abuse Treat Prev Policy 9, 39.

Cheng, J.Y., Chan, D.T., Mok, V.K., (2005). An epidemiological study on alcohol/drugs related fatal traffic crash cases of deceased drivers in Hong Kong between 1996 and 2000. Forensic Sci Int 153, 196-201.

Chu, S.K., Ma, W.K., Wong, C.W., Chu, W.H., Cheng, C.H., Wong, S., Tse, M.L., Lau, F.L., Yiu, M.K., Man, C.W., (2008). The destruction of the lower urinary tract by ketamine abuse: a new syndrome? British Journal of Urology International 102, 1616-1622.

Cloke, J.M., Winters, B.D., (2014). a $4 \beta 2$ nicotinic receptor stimulation of the GABAergic system within the orbitofrontal cortex ameliorates the severe crossmodal object recognition impairment in ketamine-treated rats: Implications for cognitive dysfunction in schizophrenia. Neuropharmacology 90, 42-52.

Copeland, J., Dillon, P., (2005). The health and psycho-social consequences of ketamine use. International Journal of Drug Policy 16, $122-131$.

Costi, S., Dam, N.T.V., Murrough, J.W., (2015). Current Status of Ketamine and Related Therapies for Mood and Anxiety Disorders. Current Behavioral Neuroscience Reports 2, 216-225.

Coyle, C.M., Laws, K.R., (2015). The use of ketamine as an antidepressant: a systematic review and meta-analysis. Human Psychopharmacology Clinical \& Experimental 30, 233-237.

Curran, H.V., Morgan, C., (2000). Curran HV, Morgan CJA. Cognitive, dissociative and psychotogenic effects of ketamine on recreational users on the night of drug use and 3 days later. Addiction 95: 575-590. Addiction 95, 575-590.

Dakwar, E., Anerella, C., Hart, C.L., Levin, F.R., Mathew, S.J., Nunes, E.V., (2014). Therapeutic infusions of ketamine: do the psychoactive effects matter? Drug Alcohol Depend 136, 153-157.

Dakwar, E., Levin, F., Foltin, R.W., Nunes, E.V., Hart, C.L., (2014). The effects of subanesthetic ketamine infusions on motivation to quit and cue-induced craving in cocaine-dependent research volunteers. Biol Psychiatry 76, 40-46.

Daskalopoulou, M., Rodger, A., Thornton, A., Phillips, A., Sherr, L., Gilson, R., Johnson, M., Fisher, M., Anderson, J., McDonnell, J., et al., (2014). Sexual behaviour, recreational drug use and hepatitis $C$ co-infection in HIV-diagnosed men who have sex with men in the United Kingdom: results from the ASTRA study. J Int AIDS Soc 17, 19630. 
De Luca, M.T., Badiani, A., (2011). Ketamine self-administration in the rat: evidence for a critical role of setting. Psychopharmacology (Berl) 214, 549-556.

Deneau, G., Yanagita, T., Seevers, M.H., (1969). Self-administration of psychoactive substances by the monkey. Psychopharmacologia 16, 30-48.

Dreizin, R.S., (1978). Drug self-administration by laboratory animals: control by schedules of reinforcement. Annual Review of Pharmacology \& Toxicology 18, 313-339.

Duan, T.T., Tan, J.W., Yuan, Q., Cao, J., Zhou, Q.X., Xu, L., (2013). Acute ketamine induces hippocampal synaptic depression and spatial memory impairment through dopamine D1/D5 receptors. Psychopharmacology 228, 451-461.

Farahmandfar, M., A, A., A, B., MR, Z., (2016). Recovery from ketamine-induced amnesia by blockade of GABA-A receptor in medial prefrontal cortex of mice. Neuroscience.

Gable, R.S., (2004). Acute toxic effects of club drugs. J Psychoactive Drugs 36, 303-313.

Giorgetti, R., Marcotulli, D., Tagliabracci, A., Schifano, F., (2015). Effects of ketamine on psychomotor, sensory and cognitive functions relevant for driving ability. Forensic Sci Int 252, 127-142.

Guo, R., Tang, Q., Ye, Y., Lu, X., Chen, F., Dai, X., Yan, Y., Liao, L., (2016). Effects of gender on ketamine-induced conditioned placed preference and urine metabonomics. Regul Toxicol Pharmacol 77, 263-274.

Hancock, P.J., Stamford, J.A., (1999). Stereospecific effects of ketamine on dopamine efflux and uptake in the rat nucleus accumbens. $\mathrm{Br} \mathrm{J}$ Anaesth 82, 603-608.

Hills, C.E., Jin, T., Siamantouras, E., Liu, I.K., Jefferson, K.P., Squires, P.E., (2013). 'Special k' and a loss of cell-to-cell adhesion in proximal tubule-derived epithelial cells: modulation of the adherens junction complex by ketamine. PLoS One 8, e71819. Honey, G.D., Honey, R.A., O'Loughlin, C., Sharar, S.R., Kumaran, D., Suckling, J., Menon, D.K., Sleator, C., Bullmore, E.T., Fletcher, P.C., (2005). Ketamine disrupts frontal and hippocampal contribution to encoding and retrieval of episodic memory: an fMRI study. Cereb Cortex 15, 749-759.

Honey, R.A., Honey, G.D., O'Loughlin, C., Sharar, S.R., Kumaran, D., Bullmore, E.T., Menon, D.K., Donovan, T., Lupson, V.C., Bisbrown-Chippendale, R., et al., (2004). Acute ketamine administration alters the brain responses to executive demands in a verbal working memory task: an FMRI study. Neuropsychopharmacology 29, 1203-1214.

Huang, L.K., Wang, J.H., Shen, S.H., Lin, A.T., Chang, C.Y., (2014). Evaluation of the extent of ketamine-induced uropathy: the role of CT urography. Postgrad Med J 90, 185-190.

Huang, M.C., Chen, L.Y., Chen, C.K., Lin, S.K., (2016). Potential benefit of lamotrigine in managing ketamine use disorder. Med Hypotheses 87, 97-100.

Huang, X., Huang, K., Zheng, W., Beveridge, T.J., Yang, S., Li, X., Li, P., Zhou, W., Liu, Y., (2015). The effects of GSK-3beta blockade on ketamine self-administration and relapse to drug-seeking behavior in rats. Drug Alcohol Depend 147, 257-265. Huang, X., Huang, K., Zheng, W., Beveridge, T.J.R., Yang, S., Li, X., Li, P., Zhou, W., 
Liu, Y., (2015). The effects of GSK-3 $\beta$ blockade on ketamine self-administration and relapse to drug-seeking behavior in rats. Drug \& Alcohol Dependence 147, 257-265. Jansen, K.L.R., Darracot-Cankovic, R., (2001). The nonmedical use of ketamine, part two: A review of problem use and dependence. Journal of Psychoactive Drugs 33, 151-158.

Jia, Z., Liu, Z., Chu, P., McGoogan, J.M., Cong, M., Shi, J., Lu, L., (2015). Tracking the evolution of drug abuse in China, 2003-10: a retrospective, self-controlled study. Addiction 110 Suppl 1, 4-10.

Kalkan, Y., Tomak, Y., Altuner, D., Tumkaya, L., Bostan, H., Yilmaz, A., Unal, D., Kara, A., Turan, A., (2013). Hepatic effects of ketamine administration for 2 weeks in rats. Hum Exp Toxicol.

Khanegheini, A., Nasehi, M., Zarrindast, M.R., (2015). The modulatory effect of CA1 GABAb receptors on ketamine-induced spatial and non-spatial novelty detection deficits with respect to $\mathrm{Ca} 2+$. Neuroscience 305, 157-168.

Krupitsky, E., Burakov, A., Romanova, T., Dunaevsky, I., Strassman, R., Grinenko, A., (2002). Ketamine psychotherapy for heroin addiction: immediate effects and two-year follow-up. J Subst Abuse Treat 23, 273-283.

Krupitsky, E.M., Burakov, A.M., Dunaevsky, I.V., Romanova, T.N., Slavina, T.Y., Grinenko, A.Y., (2007). Single versus repeated sessions of ketamine-assisted psychotherapy for people with heroin dependence. Journal of Psychoactive Drugs 39, 13-19.

Krupitsky, E.M., Grinenko, A.Y., (1997). Ketamine psychedelic therapy (KPT): a review of the results of ten years of research. J Psychoactive Drugs 29, 165-183. Kurdi, M.S., Theerth, K.A., Deva, R.S., (2014). Ketamine: Current applications in anesthesia, pain, and critical care. Anesthesia Essays \& Researches 8, 283-290. Lea, T., Prestage, G., Mao, L., Zablotska, I., de Wit, J., Holt, M., (2013). Trends in drug use among gay and bisexual men in Sydney, Melbourne and Queensland, Australia. Drug Alcohol Rev 32, 39-46.

Lee, S.T., Wu, T.T., Yu, P.Y., Chen, R.M., (2009). Apoptotic insults to human HepG2 cells induced by $\mathrm{S}-(+)$-ketamine occurs through activation of a Bax-mitochondria-caspase protease pathway. Br J Anaesth 102, 80-89.

Li, B., Liu, M.L., Wu, X.P., Jia, J., Cao, J., Wei, Z.W., Wang, Y.J., (2015). Effects of ketamine exposure on dopamine concentrations and dopamine type 2 receptor mRNA expression in rat brain tissue. International Journal of Clinical \& Experimental Medicine 8, 11181-11187.

Li, X., Li, S., Zheng, W., Pan, J., Huang, K., Chen, R., Pan, T., Liao, G., Chen, Z., Zhou, D., et al., (2015). Environmental enrichment and abstinence attenuate ketamine-induced cardiac and renal toxicity. Sci Rep 5, 11611.

Liang, H.J., Lau, C.G., Tang, A., Chan, F., Ungvari, G.S., Tang, W.K., (2013). Cognitive impairments in poly-drug ketamine users. Addictive Behaviors 38, 2661-2666.

Lindefors, N., Barati, S., O'Connor, W.T., (1997). Differential effects of single and repeated ketamine administration on dopamine, serotonin and GABA transmission in rat medial prefrontal cortex. Brain Res 759, 205-212. 
Littlewood, C.L., Jones, N., O'Neill, M.J., Mitchell, S.N., Tricklebank, M., Williams, S.C.R., (2006). Mapping the central effects of ketamine in the rat using pharmacological MRI. Psychopharmacology 186, 64-81.

Liu, Y., Le, F.B., Liu, Y., Wang, X., Lu, L., (2008). Conditioned Place Preference Induced by Licit Drugs: Establishment, Extinction, and Reinstatement. Scientific World Journal 8, 1228-1245.

Liu, Z., Lian, Z., Zhao, C., (2006). Drug use and HIV/AIDS in China. Drug \& Alcohol Review 25, 173-175.

Mason, K., Cottrell AMCorrigan, A.G., Gillatt, D.A., Mitchelmore, A.E., (2010). Ketamine-associated lower urinary tract destruction: a new radiological challenge Clinical Radiology. Clinical Radiology 65, 795-800.

Mayberg, T.S., Lam, A.M., Matta, B.F., Domino, K.B., Winn, H.R., (1995). Ketamine does not increase cerebral blood flow velocity or intracranial pressure during isoflurane/nitrous oxide anesthesia in patients undergoing craniotomy. Anesth Analg 81, 84-89.

Moreton, J.E., Meisch, R.A., Stark, L., Thompson, T., (1977). Ketamine self-administration by the rhesus monkey. J Pharmacol Exp Ther 203, 303-309. Morgan, C.J., Curran, H.V., Independent Scientific Committee on, D., (2012). Ketamine use: a review. Addiction 107, 27-38.

Morgan, C.J.A., Curran, H.V., (2006). Acute and chronic effects of ketamine upon human memory: a review. Psychopharmacology 188, 408-424.

Morgan, C.J.A., Muetzelfeldt, L., Curran, H.V., (2010). Consequences of chronic ketamine self-administration upon neurocognitive function and psychological wellbeing: a 1-year longitudinal study. Addiction 105, 121-133.

Muetzelfeldt, L., Kamboj, S.K., Rees, H., Taylor, J., Morgan, C.J., Curran, H.V., (2008). Journey through the K-hole: phenomenological aspects of ketamine use. Drug Alcohol Depend 95, 219-229.

Nakako, T., Murai, T., Ikejiri, M., Ishiyama, T., Taiji, M., Ikeda, K., (2013). Effects of a dopamine D1 agonist on ketamine-induced spatial working memory dysfunction in common marmosets. Behavioural Brain Research 249, 109-115.

Northoff, G., Richter, A., Bermpohl, F., Grimm, S., Martin, E., Marcar, V.L., Wahl, C., Hell, D., Boeker, H., (2005). NMDA hypofunction in the posterior cingulate as a model for schizophrenia: an exploratory ketamine administration study in fMRI. Schizophr Res 72, 235-248.

Pappas, M.K., Halkitis, P.N., (2011). Sexual risk taking and club drug use across three age cohorts of HIV-positive gay and bisexual men in New York City. AIDS Care 23, 1410-1416.

Pavarin, R.M., (2006). Substance use and related problems: a study on the abuse of recreational and not recreational drugs in Northern Italy. Ann Ist Super Sanita 42, 477-484.

Peng, T.R., Lee, M.C., Wu, T.W., Lan, C.C., (2014). Suspected Ketamine-associated lower urinary tract symptoms. Urology Journal 11, 1508-1510.

Penning, R., Veldstra, J.L., Daamen, A.P., Olivier, B., Verster, J.C., (2010). Drugs of abuse, driving and traffic safety. Curr Drug Abuse Rev 3, 23-32. 
Powers lii, A.R., Gancsos, M.G., Finn, E.S., Morgan, P.T., Corlett, P.R., (2015). Ketamine-Induced Hallucinations. Psychopathology 48, 376-385.

Price, R.B., Dan, V.I., Murrough, J.W., Chang, L.C., Jurdi, R.K.A., Iqbal, S.Z., Soleimani, L., Charney, D.S., Alexandra, L.F.M.S., Mathew, S.J., (2014). EFFECTS OF KETAMINE ON EXPLICIT AND IMPLICIT SUICIDAL COGNITION: A RANDOMIZED CONTROLLED TRIAL IN TREATMENT-RESISTANT DEPRESSION. Depression \& Anxiety 31, 335-343.

Reynaud-Maurupt, C., Bello, P.Y., Akoka, S., Toufik, A., (2007). Characteristics and behaviors of ketamine users in France in 2003. J Psychoactive Drugs 39, 1-11. Risner, M.E., (1982). Intravenous self-administration of phencyclidine and related compounds in the dog. J Pharmacol Exp Ther 221, 637-644.

Roberts, B.M., Seymour, P.A., Schmidt, C.J., Williams, G.V., Castner, S.A., (2010). Amelioration of ketamine-induced working memory deficits by dopamine D1 receptor agonists. Psychopharmacology 210, 407-418.

Rome, E.S., (2001). It's a rave new world: rave culture and illicit drug use in the young. Cleve Clin J Med 68, 541-550.

Romeo, B., Choucha, W., Fossati, P., Rotge, J.Y., (2015). Meta-analysis of short- and mid-term efficacy of ketamine in unipolar and bipolar depression. Psychiatry Res 230, 682-688.

Rowland, L.M., (2005). Subanesthetic ketamine: how it alters physiology and behavior in humans. Aviation, Space, and Environmental Medicine. 76, 52-58.

Rowland, L.M., Bustillo, J.R., Mullins, P.G., Jung, R.E., Lenroot, R., Landgraf, E., Barrow, R., Yeo, R., Lauriello, J., Brooks, W.M., (2005). Effects of ketamine on anterior cingulate glutamate metabolism in healthy humans: a 4-T proton MRS study. Am J Psychiatry 162, 394-396.

Shahani, R., Streutker, C., Dickson, B., Stewart, R.J., (2007). Ketamine-Associated Ulcerative Cystitis: A New Clinical Entity. Urology 69, 810-812.

Shang, Y., Wu, Y., Yao, S., Wang, X., Feng, D., Yang, W., (2007). Protective effect of erythropoietin against ketamine-induced apoptosis in cultured rat cortical neurons: involvement of PI3K/Akt and GSK-3 beta pathway. Apoptosis 12, 2187-2195.

Sheehy, K.A., Muller, E.A., Lippold, C., Nouraie, M., Finkel, J.C., Quezado, Z.M., (2015). Subanesthetic ketamine infusions for the treatment of children and adolescents with chronic pain: a longitudinal study. BMC Pediatr 15, 198.

Singh, D., Chawarski, M.C., Schottenfeld, R., Vicknasingam, B., (2013). Substance Abuse and the HIV Situation in Malaysia. J Food Drug Anal 21, S46-S51.

Skeldon, S.C., Goldenberg, S.L., (2014). Urological complications of illicit drug use. Nat Rev Urol 11, 169-177.

Solé, B., Jiménez, E., Martinez-Aran, A., Vieta, E., (2015). Cognition as a target in major depression: new developments. European Neuropsychopharmacology the Journal of the European College of Neuropsychopharmacology 25, 231-247. Stone, J., Kotoula, V., Dietrich, C., De, S.S., Krystal, J.H., Mehta, M.A., (2015). Perceptual distortions and delusional thinking following ketamine administration are related to increased pharmacological MRI signal changes in the parietal lobe. Journal of Psychopharmacology 29. 
Suzuki, T., Aoki, T., Kato, H., Yamazaki, M., Misawa, M., (1999). Effects of the 5-HT 3 receptor antagonist ondansetron on the ketamine- and dizocilpine-induced place preferences in mice. European Journal of Pharmacology 385, 99-102.

Tan, S., Lam, W.P., Wai, M.S., Yu, W.H., Yew, D.T., (2012). Chronic ketamine administration modulates midbrain dopamine system in mice. PLoS One 7, e43947. Tang, J., Liao, Y., He, H., Deng, Q., Zhang, G., Qi, C., Cui, H., Jiao, B., Yang, M., Feng, Z., et al., (2015). Sleeping problems in Chinese illicit drug dependent subjects. BMC Psychiatry 15, 28.

Tang, M., Ching, C.K., Tse, M.L., Ng, C., Lee, C., Chong, Y.K., Wong, W., Mak, T.W., Emerging Drugs of Abuse Surveillance Study, G., (2015). Surveillance of emerging drugs of abuse in Hong Kong: validation of an analytical tool. Hong Kong Med J 21, 114-123.

Tedesco, V., Ravagnani, C., Bertoglio, D., Chiamulera, C., (2013). Acute ketamine-induced neuroplasticity: ribosomal protein $\mathrm{S} 6$ phosphorylation expression in drug addiction-related rat brain areas. Neuroreport 24, 388-393.

Thompson, T., Schuster, C.R., (1964). Morphine Self-Administration, Food-Reinforced, and Avoidance Behaviors in Rhesus Monkeys. Psychopharmacologia 5, 87-94.

Tzschentke, T.M., (2007). REVIEW ON CPP: Measuring reward with the conditioned place preference (CPP) paradigm: update of the last decade. Addiction Biology 12, 227-462.

van der Kam, E.L., de Vry, J., Tzschentke, T.M., (2007). Effect of 2-methyl-6-(phenylethynyl) pyridine on intravenous self-administration of ketamine and heroin in the rat. Behav Pharmacol 18, 717-724.

van der Kam, E.L., De Vry, J., Tzschentke, T.M., (2009).

2-Methyl-6-(phenylethynyl)-pyridine (MPEP) potentiates ketamine and heroin reward as assessed by acquisition, extinction, and reinstatement of conditioned place preference in the rat. Eur J Pharmacol 606, 94-101.

Venâncio, C., Antunes, L., Félix, L., Rodrigues, P., Summavielle, T., Peixoto, F., (2013). Chronic ketamine administration impairs mitochondrial complex I in the rat liver. Life Sci 93, 464-470.

Venniro, M., Mutti, A., Chiamulera, C., (2015). Pharmacological and non-pharmacological factors that regulate the acquisition of ketamine self-administration in rats. Psychopharmacology (Berl) 232, 4505-4514.

Vernaleken, I., Klomp, M., Moeller, O., Raptis, M., Nagels, A., Rosch, F., Schaefer, W.M., Cumming, P., Grunder, G., (2013). Vulnerability to psychotogenic effects of ketamine is associated with elevated D2/3-receptor availability. Int $\mathrm{J}$ Neuropsychopharmacol 16, 745-754.

Wai, M.S., Chan, W.M., Zhang, A.Q., Wu, Y., Yew, D.T., (2012). Long-term ketamine and ketamine plus alcohol treatments produced damages in liver and kidney. Human \& Experimental Toxicology 31, 877-886.

Weeks, J.R., (1962). Experimental morphine addiction: method for automatic intravenous injections in unrestrained rats. Science 138, 143-144.

Weiner, A., Vieira, L., Ca, Bayer, M., (2000). Ketamine abusers presenting to the emergency department: a case series. Journal of Emergency Medicine 18, 447-451. 
Wilkins, L.K., Girard, T.A., Cheyne, J.A., (2012). Anomalous bodily-self experiences among recreational ketamine users. Cogn Neuropsychiatry 17, 415-430.

Winger, G., Hursh, S.R., Casey, K.L., Woods, J.H., (2002). Relative reinforcing strength of three $\mathrm{N}$-methyl-D-aspartate antagonists with different onsets of action. $\mathrm{J}$ Pharmacol Exp Ther 301, 690-697.

Wong, A., Benedict, N.J., Armahizer, M.J., Kanegill, S.L., (2015). Evaluation of adjunctive ketamine to benzodiazepines for management of alcohol withdrawal syndrome. Qualitative Market Research 9, 181-193.

Wu, S., Lai, Y., He, Y., Li, X., Guan, Z., Cai, Z., (2012). Lower urinary tract destruction due to ketamine: a report of 4 cases and review of literature. J Addict Med 6, 85-88. Xu, J.J., Zhang, C., Hu, Q.H., Chu, Z.X., Zhang, J., Li, Y.Z., Lu, L., Wang, Z., Fu, J.H., Chen, X., et al., (2014). Recreational drug use and risks of HIV and sexually transmitted infections among Chinese men who have sex with men: Mediation through multiple sexual partnerships. BMC Infect Dis 14, 642.

Yang, C., Zhou, Z.Q., Gao, Z.Q., Shi, J.Y., Yang, J.J., (2013). Acute increases in plasma mammalian target of rapamycin, glycogen synthase kinase-3beta, and eukaryotic elongation factor 2 phosphorylation after ketamine treatment in three depressed patients. Biol Psychiatry 73, e35-36.

Yek, J., Sundaram, P., Aydin, H., Kuo, T., Ng, L.G., (2015). The clinical presentation and diagnosis of ketamine-associated urinary tract dysfunction in Singapore.

Singapore Med J 56, 660-665.

Yoshizawa, K., Mori, T., Ueno, T., Nishiwaki, M., Shibasaki, M., Shimizu, N., Narita, M., Suzuki, T., (2013). Involvement of serotonin receptor mechanisms in the discriminative stimulus effects of ketamine in rats. J Pharmacol Sci 121, 237-241.

Young, A.M., Herling, S., Winger, G.D., Woods, J.H., (1981). Comparison of discriminative and reinforcing effects of ketamine and related compounds in the rhesus monkey. NIDA Res Monogr 34, 173-179.

Young, A.M., Woods, J.H., (1981). Maintenance of behavior by ketamine and related compounds in rhesus monkeys with different self-administration histories. J Pharmacol Exp Ther 218, 720-727.

Zgaia, A.O., Irimie, A., Sandesc, D., Vlad, C., Lisencu, C., Rogobete, A., Achimas-Cadariu, P., (2015). The role of ketamine in the treatment of chronic cancer pain. Clujul Med 88, 457-461.

Zhu, X., Ping, L., Hao, X., Ke, W., Su, M., Jie, L., Fei, X., Jin, J., (2015).

Ketamine-mediated alleviation of electroconvulsive shock-induced memory impairment is associated with the regulation of neuroinflammation and soluble amyloid-beta peptide in depressive-like rats. Neuroscience Letters 599, 32-37. Zhuo, X., Cang, Y., Yan, H., Bu, J., Shen, B., (2010). The prevalence of drugs in motor vehicle accidents and traffic violations in Shanghai and neighboring cities. Accid Anal Prev 42, 2179-2184. 